ЦыдЭнЭ Ширап Цыденович - аспирант, младший научный сотрудник Центра восточных рукописей и ксилографов Института монголоведения, буддологии и тибетологии СО РАН (647047, Россия, Республика Бурятия, г. Улан-Удэ, ул. Сахьяновой, 6; tsydens@outlook.com)

\title{
СОЦИАЛЬНАЯ ПОЛИТИКА БУРЯТСКИХ ВЕДОМСТВ В ХІХ - НАЧАЛЕ XХ в. И ЕЕ ОТРАЖЕНИЕ В СОВЕТСКОЙ ИСТОРИОГРАФИИ (1920-е - СЕРЕДИНА 1950-х гг.)
}

\begin{abstract}
Аннотация. Статья преследует цель определить специфические черты и результаты исследований советских историков с 1920-х до середины 1950-х гг. по проблеме социальной политики бурятских ведомств. Эти исследования затронули основные направления социальной политики бурятских ведомств. Следование за источником и положениями марксистско-ленинской методологии привели советских историков к выводу об актуальности и важности социальной политики бурятских ведомств, несмотря на ограничительные тенденции идеологического характера, которые затрагивали все направления этой деятельности. Было сформировано целостное представление об организующей роли органов самоуправления в социальной политике бурятских ведомств.
\end{abstract}

Ключевые слова: социальная политика, органы самоуправления, панмонголизм, внеэкономическая эксплуатация

$\boldsymbol{b}_{\mathrm{c}}^{\mathrm{y}}$ урятские ведомства как территориально-родовые единицы с собственным самоуправлением, созданные в соответствии с Уставом М.М. Сперанского 1822 г., имеют богатую историю в осуществлении социальной работы. Органы самоуправления занимались организацией народного образования, здравоохранения и социального призрения. Поэтому не случайно отечественная историография с 1920-х до середины $1950-$ х гг. располагает рядом исследований по этой проблеме.

Начало научной разработке проблемы в части народного образования положил очерк М.Н. Богданова, опубликованный в 1926 г. Именно он поставил вопрос о заинтересованности национального самоуправления в просвещении бурят и видел его необходимость в связи с усложнением социальной жизни [Богданов 1926: 216-217]. Он также рассмотрел историю начального образования бурят в XIX в., заострив внимание на основных проблемах школ, исследовал практику учреждения стипендий и субсидий «от волостных обществ», проблему женского образования.

В том же году опубликована первая из серии статей Ф.А. Кудрявцева о просвещении бурят, в которой на основе истории Верхнеудинского уездного училища были рассмотрены социальные и хозяйственные проблемы образования. Автор охарактеризовал стиль управления делами просвещения как чиновничий, подкрепив свою оценку примером административного надзора и делом о наказании некого учителя Федорова с угрозой увольнения и перевода в «состояние ясашных» [Кудрявцев 1926а: 103-106].

Во второй статье Ф.А. Кудрявцев впервые упоминает об Онинском, Тункинском и Селенгинском бурятских приходских училищах [Кудрявцев 1926б: 68]. Основываясь на документах за 1823-1825 гг. по училищам уезда, он обнаружил непонимание родителями пользы образования и слабое содействие органов местного самоуправления «в части просвещения» [Кудрявцев 1926б: 69]. Ф.А. Кудрявцев видел национальную особенность бурятских училищ «не 
только в преобладании бурят», но и в программе, которая включала монгольскую грамоту. Здесь же имеются полезные данные о возрастном диапазоне учащихся - «от 8 до 20 лет».

В третьей статье Федор Александрович сосредоточил внимание на особенностях участия органов самоуправления в пропаганде просвещения [Кудрявцев 1926в: 52]. Кроме того, он подтвердил практику приема на службу выпускников бурятских училищ, а также затронул вопрос содержания учащихся. В заключение исследователь пришел к мысли о том, «что буряты оказались более отзывчивыми к устройству школ и обучению, чем русские» [Кудрявцев 1926в: 53]. Он обосновал свою оценку данными по числу училищ у тех и у других. Оценка примечательна и соответствует «относительному плюрализму» исторического знания, наблюдавшемуся в 1920-1930-х гг. [Жалсанова 2012: 95], который поддерживался бурным развитием местной печати [Дондоков 1960: 56].

Четвертая статья Ф.А. Кудрявцева была опубликована в 1927 г. В ней характеризуется социальное происхождение бурятского учительства [Кудрявцев 1927: 62]. На примере тайши Баргузинской степной думы Сахара Хамнаева историк затрагивает вопрос об участии бурят в работе училищ в качестве «блюстителей» [Кудрявцев 1927: 63]. Основываясь на документах степных дум, он привел конкретные цифры расходов ведомств на образование. Кроме того, были выявлены требования, предъявляемые к бурятским детям в училищах, и отмечено влияние хозяйственных условий на ход занятий [Кудрявцев 1927: 67].

В том же году Б.П. Махатов рассмотрел вопрос об организующей роли тайши Степной думы 3. Хамаганова при открытии школы в Кударинском ведомстве. Автор указал на трудности в работе школы на первых порах с набором учащихся и в связи с малочисленностью бурятских учителей [Махатов 1927: 53].

В 1928 г. руководитель архивного управления Бурят-Монгольской АССР В.П. Гирченко в своей статье подверг критике бурятские ведомства, которые, по его мнению, не могли эффективно управлять делами просвещения. В подтверждение он привел «беспризорное состояние дел» в Хоринской степной думе в 30-е гг. XIX в. [Гирченко 1928: 16]. По мнению автора, это было закономерно по причине отсутвия в самоуправлении народного начала.

В 1929 г. в журнале «Просвещение Бурятии» была опубликована статья за подписью «Т», где была затронута проблема русификаторской роли школы, а также указаны трудности ее функционирования «в обстановке кочевого образа жизни» [Т 1929: 79-81]. В том же году В.П. Гирченко исследовал вопрос о степени доступности образования. По его мнению, нойонство стремилось закрепить доступ к образованию исключительно за собой [Гирченко 1929: 63]. На этом факте сосредоточил внимание А.И. Убугунэ, который видел в этом прямой интерес администрации для подготовки лояльного чиновничества [От царской... 1933: 14-15].

Новый импульс в разработке темы связан с майским (1934 г.) постановлением ЦК ВКП(б) и СНК СССР «О преподавании гражданской истории в школах». Для его реализации в июне 1934 г. состоялось совещание историков в г. УланУдэ, которое должно было разрешить споры, а также пресечь попытки «буржуазно-националистического» подхода в преподавании истории и сформировать «единую линию» в историческом процессе ${ }^{1}$. Совещание способствовало выработке основных положений по дальнейшей разработке истории БурятМонголии [Шестаков 1935: 90].

Таким образом, наметилась тенденция к обобщению наработанных концеп-

\footnotetext{
${ }^{1}$ Базарон Р. К совещанию по вопросам истории Бурят-Монголии. - Бурят-Монгольская правда. 1934. № 124. С. 1.
} 
ций по истории бурят-монголов и отторжению тех из них, которые не соответствовали официальной науке. Это позволило директору Института культуры Р. Базарону заявить о преодолении «национально-демократических ошибок» 1 . Однако идеологическое давление не помешало Ф.А. Кудрявцеву в 1936 г. дать смелую оценку социальной политики бурятских ведомств, которая понималась обществом как обращаемая «на общенародные нужды» [Кудрявцев 1936: 37-38]. Мнение Ф.А. Кудрявцева примечательно, если обратить внимание на события 1937 и 1938 гг, когда по обвинению в «панмонголизме» были арестованы и приговорены к расстрелу многие научные и партийные работники БурятМонголии, в т.ч. вышеупомянутый Р. Базарон [История Бурятии 2011: 125].

Историческая наука понесла огромные потери, однако заданное совещанием 1934 г. направление на расширение и углубление работы с источниками было продолжено и в 1939 г. дало первые результаты. В.П. Гирченко опубликовал сборник документов путешественников, побывавших в Сибири в XVIIXIX вв. Новые сведения подтвердили тот факт, что образование носило ограниченный характер [Гирченко 1939: 69-70]. Тем самым, источниковая база будущих исследований пополнилась фондами архивов Москвы и Ленинграда [Жалсанова 2012: 103].

Ключевым моментом в разработке проблемы стало издание в 1940 г. монографии Ф.А. Кудрявцева, в которой представлен обобщающий взгляд на вопросы открытия, финансирования и административной поддержки бурятских училищ при степных думах [Кудрявцев 1940].

Великая Отечественная война изменила привычный ход жизни всей страны, в т.ч. в исторической науке, когда исследования были переориентированы для поддержания патриотического духа населения. Хорошим примером тому служит опубликованная в 1943 г. работа Е.М. Залкинда об истории «боевого союза» и взаимного влияния бурят и русских в сферах хозяйства и культуры [Залкинд 1943].

XXIV пленум обкома ВКП(б), а затем пленум горкома ВКП(б), состоявшиеся в г. Улан-Удэ в сентября 1946 г., ознаменовали возвращение партии в привычное русло идеологической работы, что сказалось, прежде всего, на творческой интеллигенции ${ }^{2}$. В июне 1947 г. в г. Улан-Удэ прошло собрание партийного актива, на котором одобрили проведенную обкомом и горкомом ВКП(б) работу «по вскрытию и искоренению идеологических извращений» в деятельности «научных заведений» 3 . Публичные пояснения, со ссылкой на «Краткий курс истории ВКП(б)», о сущности обнаруженных «извращений» дал Б.Д. Цибиков 4 . Тем самым, обобщающие исследования стали предметом критики. В этих условиях Бурят-Монгольский научно-исследовательский институт культуры и экономики 13-16 октября 1947 г. провел совещание историков. С критическими замечаниями выступил В.И. Шунков, заявивший о наличии у историков «политически вредных извращений буржуазно-националистического характера» [Шунков 1948: 236-237]. Прежде всего подверглась критике «идеализация дорусского прошлого» и его противопоставление истории бурят после прихода русских [Шунков 1948: 224]. Осуждаемое докладчи-

1 Базарон Р. Культурное строительство в республике. - Бурят-Монгольская правда. 1934. №255. C. 2 .

2 Пленум Улан-Удэнского горкома ВКП (б). Партийная жизнь. - Бурят-Монгольская правда. 1946. № 194. С. 3.

3 Собрание актива Улан-Удэнской городской партийной организации. - Бурят-Монгольская правда. 1947. № 131. С. 2.

4 Цибиков Б.Д. О некоторых недостатках и ошибках в разработке истории БурятМонголии. - Бурят-Монгольская правда. 1947. № 150. С. 2. 
ком явление было еще в 1937 г. определено И.В. Сталиным как «местный национализм», опасность которого заключалась в стремлении к обособлению, тем самым подтачивалось «единство народов СССР» [Сталин 1937: 196]. Критика и пожелания В.И. Шункова оказали заметное влияние на разработку основополагающих задач дальнейшего изучения истории бурят-монголов [Жалсанова 2012: 106].

Спустя год А.П. Окладников рассмотрел перспективы трудоустройства выпускников бурятских училищ в XIX в. в сфере медицины [Окладников 1948: 176]. В 1951 г. был опубликован первый том «Истории Бурят-Монгольской АССР» под редакцией А.П. Окладникова, в которой Ф.А. Кудрявцев выделил сугланы как особые органы, распоряжавшиеся бюджетом социальной политики бурятских ведомств [История... 1951: 333]. Были сформулированы понятия о «комплектных» и «сверхкомплектных» учащихся [История... 1951: 427]. Кроме того, в исследовании были преодолены ошибки «буржуазно-националистического характера» [Жалсанова 2012: 107].

Социальная деятельность бурятских ведомств, помимо просвещения, также предусматривала меры по здравоохранению населения. Первым этот вопрос затронул М.Н. Богданов, который указал на отсутствие медицинского обслуживания у бурят в связи с острой нехваткой специалистов [Богданов 1926: 236]. К схожему выводу пришел С.В. Бахрушин [Бахрушин 1929: 91].

Картину дополнил В.П. Гирченко, который в 1926 г. опубликовал статью, где акцентировал внимание на работе по профилактике заболеваний населения и скота, а также по пресечению праздности [Гирченко 1926: 8].

В 1954 г. был переиздан первый том «Истории Бурят-Монгольской АССР», в котором была подтверждена фактическая недоступность медицинского ухода для бурят в рассматриваемый период [История...1954: 352]. Тем не менее следует отметить ремарку В.П. Гирченко, что «в области здравоохранения у бурят было оспопрививание», которому они обучались [Гирченко 1939: 51].

Еще одним направлением работы органов самоуправления в сфере социальной политики стало социальное призрение, на исследование которого обратил внимание академик Л.Я. Штейнберг. Он в 1927 г. рекомендовал обратить внимание на «формы взаимопомощи сородичей в нужде» [Штейнберг 1927: 130]. В.П. Гирченко связал вопрос о родовой взаимопомощи с разработкой проблемы внеэкономической эксплуатации [Гирченко 1929: 63]. На эту же проблему обратил внимание С.В. Бахрушин, который видел истоки этого явления в Уставе 1822 г. [Бахрушин 1929: 91]. Детальная разработка этой категории была произведена в ходе совещания историков в 1934 г. Формы родовой взаимопомощи стали воспринимать как инструмент эксплуатации. П.Т. Хаптаев видел выражение этих форм в отдаче «скота в пользование на прокорм» и в принуждении к труду [Шестаков 1935: 22]. Конкретизировал эту категорию В.П. Гирченко, остановившись на ренте продуктами и бесплатном труде [Шестаков 1935: 164]. Позднее П.Т. Хаптаев расширил концепцию, связав ее с развитием ростовщичества у бурят [Хаптаев 1939: 52-53].

В историческом очерке Ф.А. Кудрявцева 1940 г. была открыта для научной разработки проблема организации «хлебных экономических магазинов» [Кудрявцев 1940: 219].

Таким образом, исследования $1920-x$ - середины 1950 -х гг. затронули основные направления социальной политики бурятских ведомств. Следование за источником и положениями марксистско-ленинской методологии привели советских историков к выводу об актуальности и важности социальной политики бурятских ведомств, несмотря на ограничительные тенденции идеологического характера, которые затрагивали все направления этой деятельности. 
Тем самым, осуществленный нами историографический анализ дает возможность обобщить выводы советских историков.

Во-первых, сложилось цельное представление об организующей работе и представительской функции органов местного самоуправления бурят в деле просвещения, что проявлялось на всех доступных для бурят уровнях образования - от приходских училищ до учительских семинарий. Были затронуты основные аспекты функционирования бурятских училищ: финансы, кадры, контингент учащихся, образовательные программы, примеры взаимодействия бурятского общества с другими участниками образовательного процесса.

Во-вторых, была выявлена недоступность для бурят медицинского обслуживания, хотя встречаются сюжеты о попытках организовать в бурятских ведомствах работу по профилактике заболеваний населения и скота.

В-третьих, история деятельности бурятских ведомств по социальному призрению оказалась в наибольшей мере подверженной влиянию марксистской методологии, в результате чего была разработана концепция трансформации форм родовой взаимопомощи в формы внеэкономической эксплуатации, а органам местного самоуправления бурят была отведена роль орудия в руках эксплуататоров.

Статья подготовлена при поддержке мегагранта № W03.31.0016 «Динамика народов и империй в истории Внутренней Азиш».

\section{Список литературы}

Бахрушин С.В. 1929. Сибирские туземцы под русской властью до революции 1917 г. - Советский Север. № 1. С. 66-97.

Богданов М.Н. 1926. Очерки истории бурят-монгольского народа. Верхнеудинск: Бурмонгиз. 302 с.

Гирченко В.П. 1926. Материалы по истории хозяйства и родового управления добакайльских бурят во второй половине 18-го и в начале 19-го века. Бурятиеведение. № 2. С. 7-14.

Гирченко В.П. 1928. К истории бурят-монголов хоринцев первой половины ХІХ века. Верхнеудинск: Гостип. НКПТ. 22 с.

Гирченко В.П. 1929. Социальное расслоение среди бурят-монголов в XVIIXIX вв. (окончание) - Жизнь Бурятии. № 3-4. С. 60-65.

Гирченко В.П. 1939. Русские и иностранные путешественники XVII, XVIII и первой половины ХІХ вв. о бурят-монголах. Улан-Удэ: Бурмонгиз. 92 с.

Дондоков Б.Ц. 1960. Возникновение и развитие партийно-советской печати в Бурятии (1918-1937 гг.) Улан-Удэ: Бурятское книжное изд-во. 135 с.

Жалсанова Б.Ц. 2012. Источники и историография органов местного самоуправления бурят в ХІХ-начале ХХ в. Иркутск: Оттиск. 138 с.

Залкинд Е.М. 1943. Нерушимая дружба бурят-монгольского и русского народов. Улан-Удэ: Бурмонгиз. 29 с.

История Бурятии. Т. 3. ХХ-ХХІ вв. (отв. ред. Б.В. Базаров). 2011. Улан-Удэ: Изд-во БНЦ СО РАН. 464 с.

История Бурят-Монгольской АССР (под ред. А.П. Окладникова). 1951. УланУдэ: Бурмонгиз. Т. I. 574 с.

История Бурят-Монгольской АССР (под ред. П.Т. Хаптаева). 1954. Улан-Удэ: Бурмонгиз. Т. I. 496 с.

Кудрявцев Ф.А. 1926а. Из истории народного образования в Прибайкалье в первой четверти XIX в. - Жизнь Бурятии. № 4-6. С. 100-106.

Кудрявцев Ф.А. 1926б. Из истории народного образования в Прибайкалье в первой четверти XIX в. - Жизнь Бурятии. № 7-9. С. 64-69. 
Кудрявцев Ф.А. 1926в. Из истории народного образования в Прибайкалье в эпоху Николая I. - Жизнь Бурятии. № 10-12. С. 49-54.

Кудрявцев Ф.А. 1927. Из истории бурятского учительства в 50-60 гг. XIX в. Жизнь Бурятии. № 4-6. С. 62-68.

Кудрявцев. Ф.А. 1936. 1905 г. в Бурят-Монголии. Улан-Удэ: Бурмонгиз. 58 с.

Кудрявцев Ф.А. 1940. История Бурят-Монгольского народа от XVII в. до 60-х годов ХІХ в.: очерки. М.-Лениград. Изд-во АН СССР. 242 с.

Махатов Б.П. 1927. К истории Кударо-Бурятской школы. - Бурятиеведение. № 3-4. С. 53-55.

Окладников А.П. 1948. Из истории просвешения у западных бурят-монголов. - Записки БМНИИКЭ. Вып. 8. С. 176-177.

От иарской колонии до советской республики (под ред. М.А. Гудошникова, А.И. Убугунэ). 1933. М.-Иркутск: Тип. ОГИЗа треста «Полиграфкнига». 94 с.

Сталин И.В. 1937. Марксизм и национальный вопрос: сборник статей и речей. М.: Партиздат ЦК ВКП(б). 231 с.

Т. 1929. К истории просвещения Бурятии (Основные моменты развития народного образования в Бурятии до организации Бурреспублики). Просвещение Бурятии. № 1-3. С. 79-82.

Хаптаев П.Т. 1939. Национальное движение в Бурятии в период первой русской революции. Улан-Удэ: Бурмонгиз. 150 с.

Шестаков А.В. 1935. К истории Бурято-Монголии. - Материалы дискуссии, состоявшейся в июне 1934 г. в Улан-Удэ. М.: Тип. Известия ЦИК СССР и ВЦИК. $184 \mathrm{c.}$

Штейнберг Л.Я. 1927. Краткая программа по этнографии. - Бурятиеведение. № 3-4. С. 122-139.

Шунков В.И. 1948. Выступление на совещании историков Бурят-Монголии. 16.10.47. - Записки БМНИИКЭ. Вып. 8. С. 223-237.

TSYDENE Shirap Tsydenovich, postgraduate student, Junior Researcher at the Center for Oriental Manuscripts and Xylographs, Institute for Mongolian, Buddhist and Tibetan Studies, Siberian Branch of the Russian Academy of Sciences (4b Sakhyanovoj St, Ulan-Ude, Republic of Buryatia, Russia, 667004; tsydens@outlook.com)

\section{SOCIAL POLICY OF THE BURYAT DEPARTMENTS OF THE 19 TH - EARLY 20TH CENTURY AND ITS REFLECTION IN SOVIET HISTORIOGRAPHY (1920s - MID-1950s)}

\footnotetext{
Abstract. The article aims to determine the specific features and results of research by Soviet historians in the period from the 1920s to the mid-1950s on the problem of social policy of Buryat departments. Therefore, the task is to analyze researches on a problem and to characterize the relationship between them and the conditions in which they were produced. Soviet historians formed, in accordance with the main directions of social policy a holistic view of the organizing role of self-government in the education of the Buryats. Data were obtained on attempts to organize the work of health care. In the context of work on social charity, the transformation of forms of generic mutual assistance into forms of non-economic exploitation is considered. These results were obtained during the development of the Marxist historical concept, which, in turn, fell under the influence of ideological attitudes and had to meet the requirements of the national policy of the Communist Party. In the second half of the 1930s and in the 1940s despite the damage suffered, historians have managed to achieve results.
}

Keywords: social policy, self-government bodies, Pan-Mongolism, non-economic exploitation, social charity 